\title{
Evaluation of Spinal Instability after Single Level Fenestration Discectomy: A Prospective Study
}

\author{
Rakesh Kumar ${ }^{1}$, S S Sankhla ${ }^{2}$, R C Meena ${ }^{3}$, Lakhpat Yadav ${ }^{4}$, \\ $\mathrm{U}_{\mathrm{K}}$ Meena ${ }^{5}$, Vineet Maheshwari ${ }^{6}$ \\ ${ }^{1}$ Junior Specialist, ${ }^{2}$ Ex Senior Professor, ${ }^{3}$ Senior Professor \& HOD, ${ }^{4}$ Senior Resident,${ }^{5}$ Assistant Professor, ${ }^{6}$ \\ Resident. (Department Of Orthopaedics, S.M.S. Medical College and Hospital, Jaipur).
}

\begin{abstract}
:
Introduction: Failed back surgery syndrome (FBSS) represents a clinical condition of patients that undergo one or more surgical procedures for lumbosacral disease and still present unsatisfactory long-term relief of symptoms, with persistent or recurrent low back pain. One of the sources of failed back surgery syndrome is segmental instability of the lumbar spine. There is very limited evidence in the literature regarding the incidence of spinal instability following fenestration and discectomy.

Materials and Methods: This study was conducted on 50 patients who were between 17 and 52 years and who had undergone fenestration discectomy for a single-level lumbar intervertebral disc prolapse.

Results: Results were evaluated using Prolo economic and functional outcome scoring which showed good outcome in 41 (82\%) patients and moderate outcome in 9 (18\%) patients after fenestration. Clinical instability as per criteria was noted in $9(18 \%)$ patients post operatively while radiological instability was noted in $1(2 \%)$ patient . All $9(100 \%)$ patients with clinical instability showed a moderate outcome. $13(26 \%)$ patients showed a decrease in the disc height more than $30 \%$ as compared with there preoperative images before lumbar fenestration. Patients with radiological sign of instability showed a good outcome.

Conclusion: Standard fenestration discectomy does not destabilize the spine. Further studies are required to truly evaluate the development and progression of segmental instability in patients treated for lumbar disc herniation using different surgical methods.
\end{abstract}

\section{Introduction}

Failed back surgery syndrome (FBSS)represents a clinical condition of patients that undergo one or more surgical procedures for lumbosacral disease and still present unsatisfactory long-term relief of symptoms, with persistent or recurrent low back pain. The main etiologies of FBSS include inappropriate patient selection/diagnosis, iatrogenic instability, poor operative techniques and surgical complications. Segmental instability of lumbar spine is regarded as one of the sources of failed back surgery syndrome. [1,2,3,4].

Spinal instability is abnormal motion between two or more vertebras. However, a reasonable definition has been proposed by Pope and Panjabi [5] and Frymoyer and Selby [6]. By advocating a biomechanical approach, they defined instability as a loss of motion segment stiffness, such that force application to that motion segment produces abnormally great motion compared to that of a normal spine. In other words, instability can be defined as an abnormal response to applied loads characterized kinematically by abnormal movement in the motion segment beyond normal constraints[6].

The mechanical deformation of the intraspinal nerve tissue that induce pain and/or neurological deficits may be caused due to extensive movement. But, even a minor instability may cause irritation of the receptors related to facet joints or other components of the motion segment, resulting in local pain and/or reflexly painful muscle spasm[7].

The fenestration procedure is preferred over laminectomy to prevent the occurrence of postoperative instability, as laminectomy itself tends to result in lumbar spinal instability[8,9]. There are very limited evidence in the literature regarding the incidence of lumbar instability following fenestration and discectomy. The goal of present study, is to study the incidence of lumbar instability following single level fenestration discectomy and to study the correlation between the clinical signs, symptoms, and radiological instability with the outcome.

\section{Meterial and methods}

This study was conducted on 50 patients who were between 17 and 52 years and who had undergone fenestration discectomy for a single-level lumbar intervertebral disc prolapse and followed-up for a period of 15 years. Ethical committee approval was obtained, and patients were recruited once written informed consent had been provided. Patients with single-level disc herniation and planned for fenestration discectomy, having no instability before surgery were included in the study(figure 1,2 ). Patients who had pre operative spine instability, 
more than one level lumbar intervertebral disc prolapse, previous history of spine surgery, other associated spine pathology and psychotic patients were excluded from the study.

The patient were given general anesthesia and taken on the operating table in the knee-chest position. A lateral lumbar radiograph was then taken to confirmed the correct inter space, which was then marked. A midline incision followed by a unilateral subperiosteal dissection of the muscles and tendons from the spinous processes. The ligamentum flavum was excised till the neural tube exposed.Once the root was retracted, the bulging annulus was identified and incised in a cruciate fashion, and discectomy was performed. The target root and interspace were explored to ensure complete decompression of the thecal sac and root sleeve. Then wound was then closed. Post-operatively, patients were encouraged to walk independently on the day after surgery.. Back strengthening exercises were started as and when pain permitted. Lifting weights was permitted at 4 months of post-surgery. None of my patients had gone through revised discectomy.

On follow-up, a detailed history and clinical examination was carried out. Patients were assessed for lumbar spinal instability. The clinical criteria included "instability catch," "painful catch," and "apprehension." Instability catch was considered when the patient experienced a sudden attack of low-back pain while returning to an erect posture from a bent position. Painful catch was considered when the patient was asked to lift up his leg and let it go slowly down to the table but was unable to do so, resulting in a sudden drop of the leg due to a sharp pain in the low-back region. Apprehension was considered as being present if the patient experienced anxiety resulting from a sudden sense of collapse of the low back because of sudden onset of back pain while moving. Radiological parameters of spinal instability, sagittal displacements is the forward or backward displacement of the vertebral body measured in extreme flexion or extension respectively, while tilt is the angle measured at the vertebral end plates adjacent to the discs; a negative angle is seen in extreme extension and a positive angle is seen is extreme flexion.

The working capacity of the patient and the outcome score of surgery was assessed by Prolo economic and functional outcome score (table no. 1 and 2).

Table no.1 Prolo economic and functional outcome score.

\begin{tabular}{|c|c|c|}
\hline Score & Economic Status of patients & Functional Status of patients \\
\hline 1 & $\begin{array}{l}\text { No gainful occupation including ability to do housework/ } \\
\text { continue retirement activities }\end{array}$ & Total incapacity (or worse than before operation). \\
\hline 2 & $\begin{array}{l}\text { No gainful occupation including ability to do housework/ } \\
\text { continue retirement activities }\end{array}$ & $\begin{array}{l}\text { Mild to moderate level of back pain / sciatica (or } \\
\text { pain same as before operation but able to perform } \\
\text { active daily living). }\end{array}$ \\
\hline 3 & Able to work but not at previous occupation. & $\begin{array}{l}\text { Low level of pain and able to perform all activities } \\
\text { except sports where applicable }\end{array}$ \\
\hline 4 & Working at previous occupation part time/limited status. & $\begin{array}{l}\text { No pain but patient has had one or more recurrence } \\
\text { of LBA/Sciatica. }\end{array}$ \\
\hline 5 & ous occupation with no restrictions of any kind. & $\begin{array}{l}\text { Complete recovery, no recurrent episodes of LBA, } \\
\text { able to perform all previous activities, including } \\
\text { sports where applicable. }\end{array}$ \\
\hline
\end{tabular}

Table no.2 Grading of Prolo Economic- Functional Outcome Rating Scale

\begin{tabular}{|l|l|}
\hline $\begin{array}{l}\text { Sum of the scores given for the economic and functional status of } \\
\text { patients }\end{array}$ & Grading \\
\hline 5 & Poor \\
\hline $6-7$ & Moderate \\
\hline $8-10$ & Good \\
\hline
\end{tabular}

\section{Results}

50 patients who were followed-up, in whom 28 were men and 22 were women, with an average age of 29.3 years (17-52 years) and mean duration of symptoms was 10 months. Pre operative sign of patients are showed in table no.3. Operated levels were as follows: L4-5 $(n=28)$, L5-S1 $(n=22)$, in number. The mean duration of follow-up was 3.1 years (range 1-5 years). Before the operation, there was no radiographic or clinical instability in any of these patients.

Table no.3 Pre operative clinical sign of patients

\begin{tabular}{|l|lc|}
\hline Clinical sign & Number of patients \\
\hline Positive sciatic nerve tension sign & $50 \quad(100 \%)$ \\
\hline Motor deficit & 33 & $(66 \%)$ \\
\hline Sensory deficit & 35 & $(70 \%)$ \\
\hline
\end{tabular}


Post operatively instability in patients are showed in table no.4. Clinical instability as per criteria was noted in 9 (18\%) patients post operatively (table no. 5). The sign of "instability catch" was positive in7 of 9 (77.77\%) patients, "apprehension"in zero patient, and "painful catch" in 2 of $9(22.22 \%)$, two criteria were positive in 2 of $9(22.22 \%)$ and one criterion was positive in 7 of $9(77.77 \%)$. None of patients had all three criteria of instability. There was no correlation between neurological signs (radicular pain, motor weakness, sensory deficits) and clinical signs of instability (instability catch, apprehension, painful catch).

Table no.4 Post operatively instability

\begin{tabular}{|l|lc|}
\hline Type of instability & Number of patients \\
\hline Clinical & 9 & $(18 \%)$ \\
\hline Radiological & 1 & $(2 \%)$ \\
\hline Decrease disc hight more than $30 \%$ & 13 & $(26 \%)$ \\
\hline
\end{tabular}

Table no.5 Clinical instability post operatively

\begin{tabular}{|l|l|}
\hline Clinical sign & Number of patients \\
\hline Instability catch & $7 \quad(77.77 \%)$ \\
\hline Painful catch & $2 \quad(22.22 \%)$, \\
\hline Apprehension & 0 \\
\hline
\end{tabular}

Radiological instability was noted in $1(2 \%)$ patient and showed tilt and none of patients showed sagittal displacements. None of the patients had both tilt and displacement. 13(26\%) patient showed a decrease in the disc height more than $30 \%$ compared with the preoperative images lumbar fenestration. Patient who had showed radiological instability ,also showed loss of disc height more than $30 \%$ but they does not showed any sign of clinically instability. $9(18 \%)$ patients out of 13 patients who had a decrease in the disc height more than $30 \%$ also showed clinical instability.

The Prolo economic and functional outcome scoring showed good outcome in $41(82 \%)$ patients and moderate outcome in $9(18 \%)$ patients after fenestration. All $9(100 \%)$ patients with clinical instability showed a moderate outcome. Patient with radiological signs of instability showed a good outcome. $9(18 \%)$ patients with decrease disc height more than $30 \%$ showed moderate outcome and remaining 4(30.7\%) patients had good out come. Intra operative complication occured in one patient as dural tear. The results are found to be homogenous. Thus we does not need to include any statistical analysis.

\section{Discussion}

In the present study, the outcome of patients who underwent fenestration discectomy for lumbar disc herniation with reference to post-operative instability of the lumbar spine was analyzed. Extensive laminectomy in the treatment of spinal stenosis had been well documented to increase spinal instability[10,11]. The present study was made to seek the possibility, that lumbar disc fenestration may increase the risk of the development of single-level instability, since there are only limited data on the development and progression of spinal instability after lumbar disc surgery $[7,12,13]$. Due to the lack of clear diagnostic signs in clinical and radiological examination, there was a poor correlation between both in the present series. Adams and Hutton [14] founded the following percentage contributions by various structures in the prevention of sagittal translation: intact facet capsules (39\%), intact disc and annulus (29\%), the supraspinous and interspinous ligaments (19\%) and the ligamentum flavum (13\%).

Knutsson was the first to suggest translatory motion in the antero-posterior direction during flexionextension as an indicator of spinal instability. Similar observations have been made by others[15,16].

According to Mochida et al. postoperative narrowing of the intervertebral space following lumbar microdiscectomy is correlated to the degree of disc removal.They concluded that the younger the patient treated with massive extirpation of the disc material, the more frequently a decrease in the disc height and an increase in the intervertebral instability are seen [13]. In our study, we also founded that all the patients who had clinical instability, also had loss of disc height $>30 \%$ Kotilainen et al founded in $22 \%$ patients clinical instability after micro discectomy[7], 24\% after nucleotomy [17], in our study we founded clinical instability in $18 \%$ patients after fenestration .

The correlation between spinal instability and patients with unsatisfactory outcome was very much clear and it greatly effect there working capacity, occurrence of low back pain, and unsatisfactory outcome in daily activity.

In this study, radiological instability was noted in $1(2 \%)$ patient. Similar results had been noted in other studies too where in the radiological evidence had not correlated with the final outcome or the clinical instability $[18,19,20]$. In present scenario flexion-extension radiographs plays important role in the diagnosis of segmental instability. The clinical signs alone does not correlate with the standard radiological signs of segmental instability. It was founded that the aggravation of clinical symptoms not only effect instability of 
spine, but also lead to development other factors such as postoperative scarring and abnormal callus formation at the site of operation [11]

The functional outcome in our patients was assessed by the Prolo score that showed similar results with many earlier studies in disc surgery. The satisfactory overall outcome in $82 \%$ of our patients was agreement with the satisfactory outcome in $75 \%$ of the patients in the Kotilainen study and satisfactory outcome in $75-96 \%$ of the patients in previous studies on microdiscectomy $[21,22,23]$.

Patients who had detectable lumbar instability as a result of lumbar disc herniation. As a result, it has been hypothesized that they were those patients who were suffering from instability, sparing operative methods like microdiscectomy and even percutaneous nucleotomy might be preferred to standard surgery (fenestration discectomy) in the treatment of lumbar disc disease[7].But, the results of this study showed that this hypothesis need not necessarily be true as our results are founded to be homogenous with the results of various other studies on microdiscectomy.

The favorable outcome of this study is similar with other studies on microdiscectomy. slinical instability in $18 \%$ of our patients is in homogenous with other studies. Radiological signs of instability are seen even in asymptomatic patients and so are not as reliable as clinical signs of instability.

\section{Conclusion}

Standard fenestration discectomy does not destabilize the spine more than microdiscectomy. This procedure dose not requires expensive equipments. Further studies are required to truly evaluate the development and progression of segmental instability in patients treated for lumbar disc herniation using different surgical methods.

\section{References}

[1]. Barr JS. Protruded disc and painful backs. J Bone Joint Surg Br. 1951;33:3-4

[2]. Frymoyer JW. The role of spine fusion: Question Spine. 1981;6:284-90.

[3]. Hakelius A. Prognosis in sciatica: A follow-up of surgical and non-surgical treatment. Acta Ortho Scand (Suppl) 1970;129:3-76.

[4]. O'Brien JP, Dawson MH, Heard CW, Momberger G, Speck G, Weatherly CR. Simultaneous and combined anterior and posterior fusion: A solution for failed spinal surgery with a brief review of the first 150 patients. Clin Orthop Relat Res. 1986;203:191-5.

[5]. Pope MH, Panjabi M. Biomechanical definitions of spinal instability. Spine 1985;10:255-256.

[6]. Frymoyer JW, Selby DK. Segmental instability: rationale for treatment. Spine 1985;10:280-286.

[7]. Kotilainen E, Valtonen S. Clinical instability of the lumbar spine after microdiscectomy. Acta Neurochirurgica. 1993;125:120-6.

[8]. Garg M, Kumar S. Interlaminar discectomy and selective foraminotomy in lumbar disc herniation.J Orthop Surg (HongKong) 2001;9:15-8.

[9]. Mishra SK, Mohapatra NC, Pradhan NK, Mohapatra MK. Lumbar disc excision: Comparative study of laminectomy and interlaminar fenestration. Indian J O rthop. 1998;33:153-5.

[10]. Ebara S, Harada T, Hosono N, et al Intraoperative measurement of lumbar spinal instability. Spine. 1992,17 (3S): S44-50.

[11]. Ida Y, Kataoka O, Sho T, et al Postoperative lumbar spinal instability occurring or progressing secondary to laminectomy. Spine 1990, 15:1186-1189.

[12]. Ishihara H, Matsui H, Hirano N, et al Lumbar intervertebral disc herniation in children less than 16 years of age. Spine. 1997, 22:2044-2049.

[13]. Mochida J, Nishimura K, Nomura T, et al The importance of preserving disc structure in surgical approaches to lumbar disc herniation. Spine. 1996, 21: 1556-1564.

[14]. Adams MA, Hutton WC The mechanical function of the lumbar apophyseal joints. Spine. 1983, 8:327-330.

[15]. Knutsson F. The instability associated with disc degeneration at the lumbar spine. Acta Radiologica.1944;25:593-609.

[16]. Boden SD, Wiesel SW. Lumbosacral segmental motion in normal individuals: Have we been measuring instability properly? Spine. 1990;15:571-6.

[17]. Kotilainen E, Valtonen S Percutaneous nucleotomy in the treatment of lumbar disc herniation; results after a mean follow-up of 2 years. Acta Neurochir (Wien) 1994, 128:47-52

[18]. Amrithlal A Mascarenhas, Issac Thomas, Gaurav Sharma, and Joe Joseph Cherian, Clinical and radiological instability following standard fenestration discectomy. Indian J Orthop. 2009 Oct-Dec; 43(4): 347-351.

[19]. Frymoyer JW, Hanley EN, Howe J, Kulhmann D, Matteri RE. A comparison of radiographic findings in fusion and in non-fusion patients ten or more years following lumbar disc surgery. Spine.1979;4:435-40.

[20]. Dvorak J, Panjabi MM, Novotny JE, Chang DG, Grob D. Clinical validation of functional flexion- extension roentgenograms of the lumbar spine. Spine. 1991;16:943-50.

[21]. Ebeling U, Reichenbach W, Reulen HJ. Results of microsurgical lumbar discectomy: Review of 485 patients. Acta Neurochir (Wein) 1986;81:45-52

[22]. Goald HJ. Microlumbar discectomy: follow-up of 147 patients. Spine. 1978;3:183-5.

[23]. Pappas CT, Harrington T, Sonntag VK. Outcome analysis in 654 surgically treated lumbar disc herniations. Neurosurgery. 1992;30:862-66. 